\title{
A New Reflection of China's Developmental Approach
}

\author{
Rui $\mathrm{Li}^{1, *}$ \\ ${ }^{I}$ Master of International Relations, University of Melbourne \\ ${ }^{*}$ Corresponding author. Email: lirui330483@ gmail.com
}

\begin{abstract}
Development has always been one of the hot topics that countries around the world have been paying attention to. The recent rise of China as a development actor has raised a major question, that is what is China's developmental approach, how effective it is, and whether it can be copied by other countries. The purpose of this article is to propose my definition of China's developmental approach after reflecting on the different definitions of this concept in academia, and finally discuss its reproducibility to evaluate how China can provide references for development research. This article gives a new definition of China's developmental approach: China's developmental approach is a dynamic framework that presupposes pragmatism, flexibility, and policy sustainability, and has a series of specific elements, including play the role of government, maintain a long-term stable domestic environment, take a pilot approach, focus on infrastructure construction, and stick to the people's line. In addition, this article also believes that one of the biggest differences between China's developmental approach and other developmental models is that China's developmental approach are a provider of developmental model options rather than a careerist who forces other countries to follow. Finally, I think we can participate critically in China's development process to derive some development approaches that are worthy of reference.
\end{abstract}

Keywords: China, developmental approach, China Model, Beijing Consensus.

\section{INTRODUCTION}

Entering the 21 st century, the world is facing profound changes. However, compared with the acceleration of world change, the developmental speed of some countries, especially Western countries, does not seem to be synchronized. These countries are even facing the risk of stagnation and regression. Therefore, how a country keeps up with the pace of world change has become one of the important issues facing all countries. By contrast, China's rapid developmental achievements, especially the developmental approach behind it, have gradually become the focus of world attention. Specifically, people want to know what China's developmental approach is, why it can achieve such high achievements in such a world environment, and whether it is worth imitating and can be used by other countries as reference.

In fact, although this is a hot topic, academia still has controversy over the definition and utility of China's developmental approach. In this article, I will first try to sort out the definitions given by different scholars, and then introduce my definition from a new perspective. I compare China's developmental approach to a "box". Pragmatism, flexibility, and policy continuity constitute the framework of this "box" as the prerequisites of China's developmental approach. A series of specific elements based on these premises are the contents of this "box". Finally, this article will respond to some scholars' doubts about the repeatability and sustainability of the application of China's developmental approach, and put forward a point of view - China's developmental approach welcomes countries to refer to it, but does not force exporting.

\section{EXISTING DEFINITIONS OF CHINA'S DEVELOPMENTAL APPROACH}

The rapid development of China in recent decades, especially its economic success, has attracted a lot of attention from all parties, but whether a new universal "concept", "model" or "consensus" can be summed up from this "success" has always been controversial.

First of all, some scholars compare China's developmental model with the East Asian developmental state model. On the one hand, they note that China's developmental model is similar to the East 
Asian developmental state model [1] [2] [3] [4]. For example, Breslin believes that China's reform experiment does have some similarities with the capitalist developing countries in East Asia [1]. Baek and Karagiannis et al. present that China's development model retains some of the basic characteristics of the East Asian developmental state model, such as state intervention in the economy, instead of following Anglo-Saxon-style comprehensive economic liberalization [2] [4]. On the other hand, these scholars notice the differences between China's development model and the East Asian developmental state model. For instance, Breslin analyzes more whether China is a dysfunctional developmental model or a developmental state model, while Zhao and Karagiannis, Cherikh, and Elsner in their articles point out that China's development model can be interpreted as the $21 \mathrm{st}$ century variant or the latest successor to the experience of the East Asian development model [1] [3] [4]. However, these scholars seem to pay most of their attention to the similarities and differences between China's development model and the East Asian developmental state model, rather than making a clear generalization or definition of China's developmental model.

At the same time, other scholars adopt the notion of uniqueness, believing that China's developmental model is not a new development of other models, but is relatively independent and can even replace other models. The representative one is the "Beijing Consensus" proposed by Joshua Cooper Ramo in 2004. Ramo considers it to be an alternative global order and summarizes it into three concepts: economic growth is driven by innovation; development focuses on balance and sustainability; China's developmental path is to seek self-determination, rather than copying the blueprint for economic development of any country [5]. Compared with the ten specific recommendations put forward by the Washington Consensus, the Beijing Consensus only revolves around these three concepts. It does not impose specific policies on those who are trying to find a model of success. Instead, it is more broad and subjective. Because of this, the Beijing consensus has been controversial. Williamson, the proponent of the Washington Consensus, criticizes the lack of precise meaning of the Beijing Consensus, and mentions that Ramo only gives a vague conclusion in the end: the term is being used to describe the development policies pursued by China [6]. Coleman questions from the perspective of naming. He calls the Beijing Consensus "a notion, rather than a concept or an idea, because it does not have any of the coherence that we associate with either of those terms" [7]. However, $\mathrm{Li}$, Brodsgaard, and Jacobsen believe that the Beijing Consensus cannot be denied its rationality due to the conceptual flaws or the temporary inability to obtain the academic consensus when it is proposed [8]. In addition,
Turin points out that the Beijing Consensus is not easy to be regarded as a "model" on the surface, but the ideas that constitute it provide the basis for policy formation [9]. Generally speaking, scholars do not completely deny the value of the "Beijing Consensus", but until now there has not been any consensus on its name and definition, so it is a bit of an exaggeration to call it "consensus".

Compared with the "consensus", some scholars are more inclined to call China's developmental mode the "China Model". Coleman believes that it is important to distinguish between the "Beijing Consensus" and the "China Model" [7]. The former points to an alternative global organization, while the latter answers to the particular needs of Chinese society [7]. Additionally, in China, scholars prefer to use the "China Model" in their discourse. As $\mathrm{Yu}$ and Huang mentioned, "Other countries can learn from China's experience to develop their own paths, but the China model cannot be seen as a consensus or universal blueprint for other countries to follow" [10]. The difference is that in the Chinese context, "consensus" is usually understood as an "ideal model" widely recognized and promoted by other countries, while the "China Model" refers to a model that tells others about China's developmental experience [11]. Unfortunately, scholars have still had differences on the specific content of the "China Model". Dickson summarizes the "China Model" as three interrelated aspects, including building a national champion brand, expanding the middle class, and investing more resources to provide public products [12]. Naughton and Yang also put forward six conjectures, which may be lessons for other countries to learn [13]. Looking at these different definitions of the "China Model" respectively, they seem to be reasonable and convincing, but when compared together, they seem incomplete, especially if they cannot be persuaded by each other.

In view of the outstanding performance of China's development in recent years and the reflection on the above-mentioned existing definitions of China's development model, I think it is necessary to re-examine the definition of China's developmental model. As the UK Department for International Development (DFID) emphasized in a document, understanding China's developmental model requires not only to see the results of China's development, but also to observe the institutional arrangements and policy processes that support this achievement [14].

\section{MY DEFINITION OF CHINA'S DEVELOPMENTAL APPROACH}

The developmental approach of a country is complex, involving politics, economy, culture, diplomacy and other aspects. Therefore, it is difficult to sum it up in one sentence. It is especially true in China, a country that has a long history, unique political 
ecology, diverse culture, huge population and vast land area. Hence, I try to describe China's developmental approach from a new perspective-defining it as a "box". To put it simply, pragmatism, flexibility and policy continuity are the bases for the existence of China's developmental approach, delimiting the scope of specific policy choices. Therefore, it is a relatively fixed "box" for loading content. The specific policy is the content in the "box", which will dynamically change according to different conditions.

In addition, there is a reason for choosing "approach" instead of "model", "notion" or "consensus" for the definition. First of all, the "Beijing consensus" proposed by Ramo corresponds to the "Washington consensus." He uses the term "consensus" more to compare the "Beijing Consensus" as a new ideological substitute for the "Washington Consensus." However, he did not say too much about whether the "Beijing Consensus" is a "consensus." In fact, the concept of "Beijing Consensus" has indeed not been widely recognized, and many scholars have questioned it [7] [10] [11] [13] [15] [16].

Additionally, Coleman calls the Beijing Consensus a "notion". However, it does not seem to be appropriate to call it "notion" [7]. Although the academic circles have different definitions of China's developmental mode, researchers generally agree that several experiences, principles or laws can be extracted or summarized from the surface of China's developmental achievements [17]. For example, Dickson, Naughton, Yang and Hsu have systematically and logically summarized the characteristics of China's developmental mode, whether it is three points or six points. And "notion" often refers to a vague, general, or even fanciful idea, which seems informal or unacademic [12] [13] [17]. Obviously, China's developmental approach does not conform to it.

Compared with "consensus" to "notion" and "model" seems to be more sought after by scholars. According to the Oxford dictionary, "model" is used to describe "a person or thing eminently worthy of imitation; a perfect exemplar of some excellence." However, whether China's developmental model is worth imitating or whether it can be replicated has yet to be determined. Naughton and Yang believe that the size of the country (and the potential purchasing power of the domestic market), the abundance of labor, and the authoritarian system make China's experience difficult to replicate, but $\mathrm{Li}$, Brodsgaard, and Jacobsen believe that some of China's unique conditions that have contributed to China's development have been exaggerated [8] [13].

Based on the above viewpoints, I think the term "approach" is more appropriate. The term "approach" is relatively neutral and has no tendency to describe China's development subjectively. As for whether it is reproducible, these disputes are more reflected in the application field. In other words, they should not compete with each other in a definition that should be kept objective and cautious.

\subsection{Pragmatism}

China's development is not led by any ideological doctrine or principle, but by pragmatism [3]. As the famous Chinese saying goes, "no matter if it is a white cat or a black cat, a cat that can catch rats is a good cat." Specifically, China believes that as long as the ultimate common goal can be achieved, the kind of approach or method should be chosen is not the focus of our attention. At this point, China is not constrained by the absolute distinction between capitalism and socialism, but finds and even follows some desirable developmental experiences of capitalist developed countries, including the emphasis on the role of markets, globalization, and international trade. However, China emphasizes that pragmatism is combined with flexibility, so China does not directly copy historical experience or other countries' models, but learns selectively according to its own conditions. For example, China does not follow the liberal path that greatly weakens the role of the government, but emphasizes the important position of the government in its development.

\subsection{Flexibility}

On the one hand, flexibility means that the elements contained in this framework are dynamically changing. The point to be emphasized is that the dynamic changes here do not refer to substantial and frequent essential changes. Rather, from a long-term perspective, these elements within the framework will make necessary adjustments according to changes in specific national conditions and international situations. From a short- to medium-term perspective, these elements are relatively constant. It is because the application of some elements takes a period of time to see the effects, such as focusing on infrastructure construction.

On the other hand, flexibility means that the use of elements in the framework should focus on different specific events or different developmental stages of specific events to be dealt with. For example, in responding to the world economic crisis, the principle of "sticking to the people's line" is not obvious, but this principle plays a great role in the fight against COVID-19.

\subsection{Policy continuity}

One point that needs to be particularly emphasized is that a country's development plan usually requires a long process of research, formulation, promotion, implementation and consolidation. To ensure the smooth progress of this plan, it must be provided with a long-term stable political, economic and social 
environment. The political party plays an important role in it. Specifically, the Communist Party of China (CCP), as the only ruling party in China, exerts a huge advantage in this regard.

First of all, the long-term and sole ruling party status of CCP makes its guiding ideology consistent. In other words, after the transition of administration, the new government continues to implement the development plan formulated by the previous one. This long-term and stable support for the development plan makes its implementation more efficient. In contrast, a two-party or multi-party system is likely to face many difficulties in this regard. For example, the former US President Trump expressed dissatisfaction with Obamacare and repeatedly proposed to abolish and replace it. Regardless of the quality of Obamacare itself, as a country's official plan, it not only would be unable to receive long-term government support, but would also fall victim to partisanship and even risk a forced abolition. This actually causes an unnecessary internal consumption of national resources, which is detrimental to national development.

In addition, as the only power center, $\mathrm{CCP}$ can efficiently enrich national resources to implement development plans, and can effectively remove obstacles. This is especially obvious in some specific areas. For instance, as a pilot demonstration zone for national reforms, Pudong New Area, Shanghai can get various policy preferences to ensure the smooth progress of its pilot plan. This is called "pooling our efforts to accomplish big tasks" (集中力量办大事) in China.

It should be noted that it does not mean that a one-party system can guarantee policy continuity, while a multi-party system cannot. Based on the current situation in countries with a multi-party system, different political parties have been putting forward different opinions on a policy for the purpose of giving more points to their own party's governance and even personal careers rather than simply representing the public opinion. Such damage to policy continuity not only undermines the effectiveness of major national policies, but also violates the original intention of the multi-party system.

In general, the above three points are complementary to each other and form the "box" of China's developmental approach. It can be summarized simply as follows: Because of pragmatism, China's developmental approach must be able to adjust flexibly to adapt to new realities, and meanwhile, policy continuity limits absolute flexibility to a certain extent, making policies pragmatic and efficient. Under these three premises, China's developmental approach adopts different specific policies at different stages or when in response to different events, which can be roughly summarized as the following five elements

\subsection{Elements}

As mentioned above, due to the flexibility of this "box", the elements within the framework are in a state of dynamic change for a long time, but they are relatively fixed in the short- and medium-term time frame. Therefore, the five elements summarized in this article are based on the basic principles of China's development in the past 20 years, that is, the period since the 21 st century.

\subsubsection{Play the role of government}

China attaches great importance to the government's role in national development, especially economic development. This role can be roughly divided into three aspects: the government formulates development plans; the plan is integrated with the market; and the government supports state-owned enterprises.

First, compared with other countries, the Chinese government pays more attention to the formulation and implementation of development plans. These strategic plans point out the direction for China's development. Moreover, the development of a country cannot be achieved overnight, and may even require decades or hundreds of years of persistent efforts. In this case, a relatively well-considered, well-arranged, and far-sighted plan becomes particularly necessary.

Second, China has established socialist market economy to a large extent, including the establishment of a stock market, accession to the WTO, and active integration into the international market. However, China has a negative attitude towards complete economic liberalization. China believes it needs to strike the right balance between planning and markets, which is the combination of market and plan. This view of China was confirmed in the 2008 global financial crisis. For example, although the United States has always defended American-style free enterprises and has believed that they are not the culprits that caused the global financial crisis, its $\$ 700$ billion rescue plan and a rescue plan that calls for global coordination have in fact proved the necessity and effectiveness of the combination of market and plan.

Third, state-owned enterprises have always occupied a vital position in China's development process. Most western scholars believe that such government-controlled enterprises lack competition and are prone to corruption, but the great advantages of state-owned enterprises have been ignored. On the one hand, state-owned enterprises are not completely without competition, but at least two in each field exist at the same time. For example, in the telecommunications industry, there are three companies: 
China Mobile, China Telecom, and China Unicom. On the other hand, while state-owned enterprises use their monopoly position to obtain profits, they must also assume more social responsibilities due to their state-owned attributes, especially in some basic public services. For instance, China's state-owned enterprises cooperate with the state to connect water, electricity, and networks to remote areas to solve basic living problems for local residents. In this regard, there is no profit at all, but a huge long-term investment in costs.

Furthermore, this is even more prominent when the country is facing a sudden crisis. The 2008 Sichuan earthquake is a great example. After the earthquake, China could quickly summon professional teams from various state-owned enterprises in water conservancy, power, communications and engineering to the disaster-hit areas for emergency rescue and repair, and restore the supply of local infrastructure such as water, electricity and other facilities in the shortest possible time. And because of the state ownership, the charges for these basic public services did not rise during this period, and even the state-owned enterprises took the initiative to bear them. Compared with the situation in Texas in the United States in 2021, when electricity bills soared nearly 200 times due to extreme weather and large-scale blackouts, the advantages of China's state-owned enterprises in terms of people's basic living security are self-evident.

\subsubsection{Maintain a long-term stable domestic environment}

Chinese leaders are clearly aware that a stable environment is a prerequisite for national development, so they have always emphasized the importance of "stability" [8]. Especially during Hu's administration, China put forward the idea of "building a harmonious socialist society". In the Chinese context, "harmony" and "stability" in this thought have similar meanings.

The environmental stability that China attaches importance to is mainly divided into political environment stability and economic stability. On the one hand, China believes that economic reform should take precedence over politics, so that the country can directly implement the formulated development plan without interference. Otherwise, no matter how good the plan is, it will not be implemented or even abandoned due to partisan struggle or political change. This is different from the claims of some supporters of the Washington Consensus. They believe that because the political system will directly affect every economic activity, political reform must precede economic reform; in other words, political correctness can ensure that economic costs are minimized [18] [19]. Nevertheless, if political reform is launched in the first place, it is likely to repeat the mistakes of European "shock therapy" reforms. China has learned a lesson from this and firmly believes that economic development should be placed before political reform. Many scholars agree with this view and believe that a significant reason behind China's rapid economic growth in recent years is its relatively stable domestic political environment [13] [20] [21]. As stated by Asia Times, due to the relatively stable domestic political environment, successful economic performance enables China to gradually make political adjustments in the future [22].

On the other hand, in terms of economy, China is not radical and leapfrog even on economic reform. Instead, China believes that a stable economic environment is a prerequisite for a series of economic reforms, and the purpose of economic reforms is to also have a long-term stable and well-functioning economic environment. Therefore, China pays more attention to keeping the economic environment stable. For instance, Premier Li Keqiang particularly emphasizes "the policy of maintaining stability in six areas" (六稳政策) and “the policy of guaranteeing six areas” (六保政策).

Facts have proved that having a stable domestic economic environment is crucial to China's economic development. From a long-term development perspective, according to data from the World Bank, China's gross domestic product (GDP) rose from 5.102 trillion in 2009 to 14.343 trillion in 2019, maintaining a good growth momentum [23]. From the perspective of risk resistance, while China is fighting the COVID-19 epidemic in 2020, economic operations have been improving quarter by quarter and gradually returning to normal. China is the only major global economy that has achieved positive economic growth in 2020 [24].

\subsubsection{Take a pilot approach}

The pilot approach is to implement reforms in a specific province or region, rather than to implement unproven reforms in the entire society at once [6]. Exploring development paths in this way is one of the key characteristics of China's developmental approach that many scholars have paid attention to [3] [6] [16] [17]. It is well-known in the economic field and has achieved a certain degree of success, such as "Reform and Opening" policy implemented of the last century. Nevertheless, the pilot approach is not limited to the economic field, but is carried out in various fields. For instance, China is experimenting with new methods of providing social welfare. Shanghai took the lead in experimenting with a feasible contract-based model, inviting NGOs to bid for government contracts to provide citizens with social benefits [25].

There are many benefits of exploring development paths in this way. First, reform is a break from the old state, so it would inevitably face some obstacles. Experimenting in some places where conditions are easy 
to implement can serve as a demonstration or propaganda role, dissolving some people's misunderstandings and doubts, and reducing obstacles to later popularization across the country. Second, as the famous Chinese saying goes, practice leads to true knowledge. No matter how complete the preliminary plan is, the reform will face some unexpected problems in its actual implementation. Testing is a process of discovering problems and making continuous improvements. Even if the test failed, the loss would not be large because the testing area is in small range. This would reduce the risk of failure to promote some new policies rashly across the country.

\subsubsection{Focus on infrastructure construction}

China's large-scale investment in infrastructure has attracted worldwide attention, and this is also one of the characteristics of China's developmental approach that many scholars agree with. In this regard, there is a famous Chinese saying, "if we want to get rich, we must first build roads", which clearly expresses the importance of infrastructure construction for development. According to statistics, from 1996 to 2018, investment in China's transportation industry grew at an average annual rate of $16.7 \%$ [26]. It is worth noting that, in addition to transportation, energy, and drinking water, China's investment in infrastructure has expanded to new areas such as environmental protection, life support, and information networks.

The advantages of focusing on infrastructure construction are significant. In the short term, it can quickly make up for the country's shortcomings in infrastructure and solve part of the employment problem simultaneously. In the long run, infrastructure usually has a long life cycle. In other words, once it is built, it can benefit a country for decades or even a hundred years. Some scholars here questioned that from the perspective of economic benefits, it takes a long time to recover costs and obtain economic benefits from it. For instance, Ansar et al. note that in more than half of China's infrastructure investments in the past three decades, the cost is greater than the benefits it generates, which means that these projects destroy rather than create economic value [27]. However, they neglect other values and hidden values of infrastructure construction. Take the highway as an example. Many expressway projects in China cannot generate positive returns, but the highly developed road network lays the foundation for social development and narrows the regional gap. Just like building a tall building, there is no way to build a skyscraper without consolidating the solid foundation. Infrastructure construction is the foundation of the national development of the skyscraper.

\subsubsection{Stick to the people's line}

Adhering to the people's line is a principle often mentioned by the Chinese government. To put it simply, it means insisting on following a mass line that everything the government does is for the masses, everything depends on the masses, from the masses to the masses. This is already expressed in Hu's so-called “Three Closenesses" (三个靠近), a careful refinement of Jiang's “Three Representatives” (三个代表): to be close to reality, close to the people and close to life [5]. In addition, whether it is to "serve the people wholeheartedly" as the fundamental purpose of the Chinese Communist Party (CCP), or to name the army after the word "people", it shows that China attaches great importance to this line. In reality, China's development embodies this principle everywhere. For example, the "maximum run once" government service reform pioneered in Zhejiang Province was carried out from the perspective of making things easier for the people. Specifically, adherence to the people's line is manifested in two aspects: focusing on people's livelihood and forming a relationship of mutual trust with the people.

On one hand, China solves people's livelihood problems by providing public products to achieve social stability and improve people's happiness, such as education, medical care, and employment [17]. The poverty alleviation policy (扶贫政策) is one of the important national strategies covering all these aspects. According to the 13th Five-Year Plan for Poverty Alleviation, it refines the relevant paths and measures from many aspects, including industrial development, employment, education, medical and health care, ecological protection, social security [28]. This policy can not only reduce the risk of social instability by reducing the poverty population, but also promote the social development of the country, especially in poor areas, in the process of implementation.

Simultaneously, the country's adherence to the people's line earns the people's trust in the country. The statistics show that the Chinese people have high levels of trust in four central-level political institutions, including the national government, the NPC (national legislature), the CCP, and the People's Liberation Army [29]. The percentage of distrust of these institutions is by far the lowest in Asia [29]. This high degree of mutual trust between the people and the government, political parties, and the armed forces can form a strong cohesion and centripetal force in the development.

It is worth noting that this way of considering national development from the perspective of the people is different from that of Western countries. Many of China's specific development policies are directly implemented on every Chinese person. By contrast, the "Washington Consensus" is the perfect guide for an economy to attract foreign capital, but it does not seem to have anything to do with directly improving people's 
lives [5]. The way of taking the mass line requires continuous high-cost investment but has no direct economic benefits. However, in the long-term development, treating the "people" as the main body of the country's development is more conducive to the development of strength and the maintenance of long-term stability of the country. This is also in line with the traditional Chinese political principle that "water can carry a boat and it also can overturn it." The "water" here refers to the people, and the "boat" refers to the government.

Finally, it should be noted that the above-mentioned five points do not include the "innovation" that many scholars mention. This is because China's encouragement of independent innovation is not so much a specific feature of China's developmental mode, but rather a call to all levels of society to adhere to pragmatism and flexibility. Whether it is institutional innovation at the national level or technological innovation at the enterprise level, they are actually pragmatic and flexible decisions or adjustments made after keen judgment on the development trend of the current era and their own conditions.

\section{THE APPLICATION OF CHINA'S DEVELOPMENTAL APPROACH TO OTHER COUNTRIES}

In the study of China's developmental approach, the focus of some scholars is not on a complete and exact definition of China's developmental approach, but whether it is reproducible and sustainable. Supporters argue that the Chinese way of development can serve as a global alternative order or solution [5] [8], while opponents argue that China's developmental approach are too specific and uncertain to be copied or even succeed in the long run [13] [17]. However, this article gives a new point of view: China's developmental approach does not have the so-called universality of the West, and China does not advocate forcing it to export. The greatest value of China's developmental approach to other countries is that China has proved that the country's developmental approach is diversified, and countries can pragmatically and flexibly choose the method that suits their country, that is, seize the initiative. Specifically, China's developmental approach provides countries with some successful experiences and some specific policies that can be used for reference. However, it is up to other countries themselves to decide whether to learn from these developmental methods, and the extent and scope of the lessons. China just shares them with the world.

Based on the above point of view, the replicability of China's developmental approach are different from its generally stated. First, China's developmental approach does not mean to provide a perfect development plan that can be copied directly. Li, Brødsgaard and Jacobsen mention that China's developmental approach should be regarded as flexible guidelines [8]. In the final analysis, what really matters is how creatively a country can learn from other places to adapt to its own national conditions. After all, no country is exactly the same. Even the "Washington Consensus", a relatively recognized model in Western countries, has different applications in different countries. This is precisely the flexibility and pragmatism that China's developmental approach has always emphasized. China's developmental approach is a box containing some reference elements that China has explored through its own development. Different countries can choose the degree, scope and content of emulation according to their own conditions.

Second, it is undeniable that China has some special national conditions. For example, Naughton and Yang believes that China has three special basic characteristics: a huge potential domestic market; a rich labor force; an authoritarian political system [13]. These special conditions are the factors contributing to China's development. But their importance cannot be absolute. Moreover, these conditions may not be entirely positive factors for China's development. For example, China's huge population can indeed provide a large amount of labor, but at the same time the huge population is also a heavy burden for development. Even today, China has outstanding total data in various fields, but the per capita data is still not high. Therefore, China's development is not simply due to some special conditions, but there is indeed a kind of China's developmental approach that is worth studying.

Third, abundant facts prove that China's developmental model can be used well in other countries. For example, African countries learn from China and cooperate with China to invest in infrastructure construction. Tovar points out in two case studies of The Addis Ababa-Djibouti Railway in Ethiopia and Djibouti and the Abuja-Kaduna Rail Line in Nigeria, strengthening the construction of infrastructure can not only provide important commercial and passenger flow routes for the local area to promote economic development, but also provide a large number of jobs [30]. It is worth emphasizing that a group of skilled workers have been trained in the process of infrastructure construction. After completing this project, they can continue to use the learned technology to contribute to the development of local related fields.

\section{CONCLUSION}

Through combing the different views on China's developmental approach, it can be concluded that although there is no clear definition of China's developmental approach, people generally realize the importance of exploring China's developmental approach and drawing some lessons from it. This article 
gives a definition of China's developmental approach from a new perspective: China's developmental approach are a dynamic framework that presupposes pragmatism, flexibility, and policy sustainability, and includes a series of specific measures. The main specific measures currently include playing the role of government, maintaining a long-term stable domestic environment, taking a pilot approach, focusing on infrastructure construction, and sticking to the people's line. In addition, this article also believes that one of the biggest differences between China's developmental approach and other developmental models is that China's developmental approach are a provider of developmental model options rather than a careerist who forces other countries to follow. China has never considered China's developmental approach to be a perfect and universal developmental method, but provides some reference experiences and new possibilities for national development. China hopes that other countries can get inspiration from China's developmental approach and apply them to their own countries.

It is necessary to engage in development research related to China, because people are eager to understand China's development trajectory, and because of China's growing role as a development actor [17]. What needs to be emphasized is that because China's developmental approach is not perfect and are in a state of advancing with the times, its flaws and limitations cannot be ignored, but from a long-term macro perspective, China's developmental approach are still worthy of recognition.

For future research, more case studies can be introduced, so as to have a deeper understanding of China's developmental approach under actual conditions. In addition, we can further pay attention to and compare the development approach of China and other countries, especially the similarities and differences with the development methods of the United States, so as to explore more lessons for national development

\section{REFERENCES}

[1] S.G Breslin, China: Developmental State or Dysfunctional Development?, Third World Quarterly, 17 (4), 1996, pp. 689-706. DOI: https://doi.org/10.1080/01436599615326

[2] S.W. Baek, Does China Follow "the East Asian Development Model"?, Journal of Contemporary Asia, 35 (4), 2005, pp. 485-498. DOI: https://doi.org/10.1080/00472330580000281

[3] S. Zhao, The China Model: Can It Replace the Western Model of Modernization?, Journal of Contemporary China, 19 (65), 2010, pp. 419-436. DOI: https://doi.org/10.1080/10670561003666061
[4] N. Karagiannis, C. Moula, E. Wolfram, Growth and Development of China: A developmental State 'with Chinese Characteristics', Forum for Social Economics, 2021, pp. 1-19. DOI: https://doi.org/10.1080/07360932.2020.1747515

[5] J.C. Ramo, The Beijing Consensus, Foreign Policy Centre, 2004.

[6] J. Williamson, Is the "Beijing Consensus" now Dominant?, Asia Policy, no. 13, 2012, pp.1-16. DOI: 10.1353 /asp.2012.0012

[7] W.D. Coleman, Beijing Consensus: Beijing "Gongshi." Who Recognizes Whom and to What End?”, Political Science.

[8] X. Li, K.E. Brodsgaard, M. Jacobsen, Redefining Beijing Consensus: Ten Economic Principles, China Economic Journal, 2 (3), 2010, pp. 297-311. DOI: https://doi.org/10.1080/17538960903529535

[9] D.R. Turin, The Beijing Consensus: China's Alternative Development Model, Student Pulse, 2 (1), 2010, pp. 386-405.

[10] K. Yu, P. Huang, China Model: Experience and Lessons, in S. Xie (Eds.), The China Model and the 'Beijing Consensus': beyond the 'Washington Consensus', Social Science Literature Press, pp. 11-20.

[11] L.H. Chan, P.K. Lee, G. Chan, Rethinking Global Governance: A China Model in the Making?, Contemporary Politics, 14 (1), 2008, pp. 3-19.

[12] B.J. Dickson, Updating the China Model, The Washington Quarterly, 2011, 34 (4), pp. 39-58. DOI: https://doi.org/10.1080/0163660X.2011.608335

[13] B.J. Naughton, D.L. Yang, Holding China Together: Diversity and National Integration in the Post-Deng Era, Cambridge University Press, Cambridge, 2004.

[14] China: Development Research Priorities. Report on Consultations for DFID's Global Research Strategy 2008-2013, Technical report, Institute of Development Studies University of Sussex, Brighton, UK, 2007.

[15] A.Y. So, The Chinese Model of Development: Characteristics, Interpretations, Implications, Perspectives on Global Development and Technology, 13 (4), 2014, pp. 444-464. DOI: https://doi.org/10.1163/15691497-12341311

[16] R. Tim, How Does China Impact the Future International Political Order? Conceptual Reflections of the "China Model" in Light of China's Fragmented Polity, International Relations 
4 (1), 2016, pp. 4859.

[17] J.Y.J. Hsu, China's Development: A New Development Paradigm?, Third World Quarterly, 36(9), 2015, pp. 1754-1769. DOI: https://doi.org/10.1080/01436597.2015.1046985

[18] D.C. North, Institutions, Institutional Change and Economic Performance, Political Economy of Institutions and Decisions, Cambridge University Press, $\quad$ Cambridge, $1990 . \quad$ DOI: https://doi.org/10.1017/CBO9780511808678

[19] R.H. Coase, The Nature of the Firm, Economica, 4 (16), 1937, pp. 386-405. DOI: https://doi.org/10.1111/j.1468-0335.1937.tb00002.x

[20] A.J. Nathan, China's Changing of the Guard: Authoritarian Resilience, Journal of Democracy 14 (1), 2003, pp. 6-17. DOI: https://doi.org/10.1353/jod.2003.0019

[21] K.E. Brødsgaard, Y. Zheng, Bringing the Party Back in: The Role of the CCP in Governing China, Routledge, 2004.

[22] The Dragon's Metamorphosis, Beach, Sophie, December 9, 2006, https://chinadigitaltimes.net/2006/12/the-dragonsm etamorphosis-david-gosset/

[23] GDP Growth (annual \%) | Data, the World Bank, June 18, 2021, https://data.worldbank.org/indicator/NY.GDP.MKT P.KD.ZG?end $=2010$ \&start $=2007$

[24] China Government Work Report. 2021. Technical report. Beijing, China: State Council of China, March.

[25] K. Simon, J. Teets, Revolutionizing Social Service Delivery in China: The New Policy of Contracting Out to Non-Profit Organizations, International Journal of Civil Society Law, 2014.

[26] Why can China's Infrastructure Lead the World?, People's Daily, September 18, 2019, https://baijiahao.baidu.com/s?id=16449780354157 $02654 \& w f r=$ spider $\&$ for $=$ pc

[27] A. Ansar, B. Flyvbjerg, A. Budzier, D. Lunn, Does Infrastructure Investment Lead to Economic Growth or Economic Fragility? Evidence from China, Oxford Review of Economic Policy 32 (3), 2016, pp. 360-390. DOI: https://doi.org/10.1093/oxrep/grw022

[28] The 13th Five-Year Plan for Poverty Alleviation, Chinese State Council, November 23, 2016, http://www.gov.cn/zhengce/content/2016-12/02/con tent_5142197.htm

[29] T. Shi, 9. China: Democratic Values Supporting an
Authoritarian System, in Y.H. Chu, L. Diamond, A.J. Nathan, D.C. Shin, How East Asians View Democracy, New York Chichester, Columbia University Press, West Sussex, 2008, pp. 209-237. DOI: https://doi.org/10.7312/chu-14534-011

[30] A. Tovar, Chinese Infrastructure Investments in Africa: A Case Study of the Addis Ababa-DjiboutiRailway in Ethiopia and Djibouti and the Abuja-Kaduna Rail Line in Nigeria, Senior Theses, vol. 25, 2019, pp. 1-38. 